\title{
Experimental transmission of segmented filamentous bacteria (SFB) in rainbow trout Oncorhynchus mykiss
}

\author{
Ú. McCarthy $^{1, *}$, R. Pettinello ${ }^{2}$, L. Feehan ${ }^{1}$, Y. M. Ho ${ }^{1}$, P. White ${ }^{1}$ \\ ${ }^{1}$ Marine Scotland Science, Marine Laboratory, Aberdeen AB11 9DB, UK \\ ${ }^{2}$ School of Biological Sciences, University of Aberdeen, Aberdeen AB24 2TZ, UK
}

\begin{abstract}
Rainbow trout gastroenteritis (RTGE) has been the cause of acute mortality in farmed rainbow trout in Europe since 1992. Epidemiological analysis has indicated a strong association with high production levels and suggested an infectious aetiology. The condition is characterised by the presence of large numbers of segmented filamentous bacteria (SFB) in the intestine, but the role of these in the disease has not been confirmed, in part because the organisms cannot be cultured. Therefore, other approaches need to be developed to investigate the role of SFB in RTGE. Faecal material from clinically affected RTGE trout, either untreated or heat-inactivated, was administered to fish from a susceptible stock, to determine whether the SFB could be transferred artificially and survive in or colonise the new host. Using histology and nested PCR, SFB were detected in the pyloric caeca of fish 23 to $30 \mathrm{~d}$ after challenge with untreated faeces. Histological changes in the intestine and the presence of an unidentified Gram-negative coccus were also significantly associated with exposure to untreated faeces. Upregulation of IFN- $\gamma$, IL-17A/F and IL22 gene expression in proximal intestine suggested a low-level immune response to the challenge.
\end{abstract}

KEY WORDS: Pyloric caeca $\cdot$ Intestinal pathology $\cdot$ Immune gene expression

\section{INTRODUCTION}

Rainbow trout gastroenteritis (RTGE) was first reported from farmed rainbow trout Oncorhynchus mykiss (Walbaum) in Spain and France during the 1990s (Michel et al. 2002). Mortalities occurred during summer months when water temperatures were above $15^{\circ} \mathrm{C}$ and began suddenly, often following an environmental or handling stress. Signs of disease included the production of yellowish mucoid faeces and distension of the abdomen accompanied by acute enteritis with extensive congestion and haemorrhage. The digestive tract was filled with a mucoid material which formed a plug in the terminal region, and large numbers of segmented, filamentous micro- organisms were observed. Segmented filamentous bacteria (SFB) have long been reported from a range of vertebrates, and Urdaci et al. (2001) designed PCR primers to amplify the 16S rRNA (rrs) gene, by aligning published sequences. The sequenced rrs gene from RTGE-affected trout in Spain was found to be closely related to other vertebrate SFB sequences and was detected only in RTGE-affected fish (Urdaci et al. 2001).

The first recorded incidence of RTGE in the UK was from a site in southern England in 2000 (Branson 2003). By 2006, the condition had been reported from an additional 11 farms, including sites in Scotland (Del-Pozo et al. 2009). In this latter study, epidemiological examination of risk factors including environ- 
mental, site and management variables indicated that feeding strategies (automated/demand feeding systems, higher mean feed input per individual fish weight) might play a role in development of RTGE (Del-Pozo et al. 2009, 2010a). However, the pattern of incidence also suggested an infectious aetiology, although treatment with antibiotics appeared to alleviate rather than clear the condition (Del-Pozo et al. 2010a). Del-Pozo et al. (2010b) detected SFB rrs DNA in tissue sections of pyloric caeca or distal intestine, and in fresh digestive contents of both RTGEaffected and cohabiting trout. However, SFB DNA was also detected in apparently healthy fry from unaffected production units (Del-Pozo et al. 2010b). Thus, the relationship, if any, between the presence of SFB and RTGE is still unclear.

SFB have been recorded in a wide variety of vertebrates, including rodents, primates, birds, amphibians (Xenopus laevis) and carp (Klaasen et al. 1993a, Urdaci et al. 2001), but, until recently, it has not been possible to culture them. The in vitro cultivation of murine SFB has only lately been achieved and was dependent on the availability of SFB mono-associated mice (Schnupf et al. 2015). The attachment of SFB to the epithelial cells of the ileum of rats and mice, their lifecycle and the production of endospores was reported by Davis \& Savage (1974) and Chase \& Erlandsen (1976). Molecular analysis indicated that vertebrate SFB form a distinct group within the Clostridium subphylum (Snel et al. 1995), for which Thompson et al. (2012) proposed the name Candidatus Savagella. The bacteria exhibit host species specificity even between closely related host species (Tannock et al. 1984), and it is thought that SFB from each host represent a different species which may have coevolved with the host (Snel et al. 1995). They are considered to be important in the development and function of the host immune system (Klaasen et al. 1993b, Gaboriau-Routhiau et al. 2009), and MHC II-dependent antigen presentation of SFB antigens by intestinal dendritic cells is crucial for induction of Th17 cells in the lamina propria of mice (Goto et al. 2014). However, their ability to stimulate the mucosal immune system has also been suggested to play a role in the pathogenicity of diseases (Talham et al. 1999), and SFB have been shown to exacerbate inflammation in models of disease, such as autoimmune arthritis (Wu et al. 2010). While SFB colonisation usually decreases with age, it can increase in a number of disease conditions, e.g. inflammatory bowel disease of humans (Yin et al. 2013, Ericsson et al. 2014) and necrotic enteritis disease of chickens (Stanley et al. 2014). Incidence is also influenced by factors including diet and stress (Klaasen et al. 1993a).

The presence of SFB, as well as enterocyte detachment and congestion in the distal intestine or pyloric caeca, is used in histopathological diagnosis of RTGE (Del-Pozo et al. 2010c). However, studies on the link between SFB and RTGE have been hampered by the inability to culture trout SFB and the lack of a straightforward challenge model. Therefore, the following aquarium-based experiment was carried out to determine whether the organisms could be transmitted artificially, using fresh faecal material from SFB-positive trout to inoculate recipient fish by oral gavage. It is considered by some members of the Scottish trout industry that RTGE is triggered by feeding to a high daily ration at temperatures at or above $16^{\circ} \mathrm{C}$, and consequently, these parameters were taken into account in the experimental protocol. Nested PCR was carried out to detect the SFB rrs gene in the pyloric caeca of recipient fish at various times following challenge. Paraffin-embedded tissue sections of pyloric caeca and intestine of recipient trout were also screened microscopically to detect colonisation by SFB and other pathological changes. Expression in the pyloric caeca of selected cytokines relevant to inflammation or gut-associated immunity (interleukin [IL]-1 $\beta$, IFN $\gamma$, IL-17A/F and IL-22; Monte et al. 2011, 2013) was examined to detect host responses following challenge.

\section{MATERIALS AND METHODS}

\section{Ethics statement}

All handling of fish was conducted in accordance with the Animals (Scientific Procedures) Act 1986, and all proposed experiments were first subject to detailed statistical review to ensure that a minimum number of fish was used which would allow statistically meaningful results to be obtained.

\section{Fish}

Rainbow trout of a known RTGE-susceptible stock were transferred from a freshwater hatchery in Scotland to aquarium facilities at the Marine Scotland Science (MSS) Marine Laboratory. The transfer took place in late April when the fish weighed approximately $23 \mathrm{~g}$. RTGE has not been reported in fish at the hatchery site. The fish were divided into 2 groups of 100 and held in $2 \mathrm{~m}$ flow-through tanks supplied 
with fresh water at approximately $1000 \mathrm{l} \mathrm{h}^{-1}$. The fish were fed the same diet as their commercially reared counterparts, i.e. Royale Horizon LA diet (40\% protein, $28 \%$ oil; Skretting). These were designated 'recipient' fish and were held under conditions believed to be permissive to the development of RTGE, i.e. they were fed to the 'Fastrack' maximum recommended daily rations appropriate for weight and water temperature according to the manufacturer's feed tables, 1.6 to $2.3 \%$ body weight per day (bw $\mathrm{d}^{-1}$ ). In addition, the fish were held at ambient water temperature, which increased from $9.3^{\circ} \mathrm{C}$ at the beginning of May to a maximum of $17.6^{\circ} \mathrm{C}$ in midJuly (a period of approximately $11 \mathrm{wk}$ ). Thereafter, water temperatures gradually decreased to $15.3^{\circ} \mathrm{C}$ over the next $25 \mathrm{~d}$, at which time the fish were transferred to the challenge tanks and maintained at $16^{\circ} \mathrm{C}$. Prior to the challenge, samples of internal organs were collected from 13 fish for histopathological examination to check for the absence of SFB (in haematoxylin and eosin [H\&E] or in Gram-stained sections of pyloric and distal intestine) and for the absence of other bacteria or indication of disease (H\&E).

\section{Experimental challenge protocol}

In early August, 64 moribund rainbow trout were transported alive to the Marine Laboratory aquarium, from a pond on a freshwater production site undergoing an outbreak of RTGE. At the time of the outbreak, the feeding rate on site was 1.6 to $1.8 \%$ bw $\mathrm{d}^{-1}$ Horizon diet, in accordance with feed tables. On arrival, these donor fish were euthanised using $200 \mathrm{mg} \mathrm{l}^{-1} \mathrm{MS}-222$. The surface of each fish was sterilised by swabbing with $70 \%$ ethanol, and faecal material was expressed from the anus by gentle stroking. The pooled material was mixed at intervals during collection and before use, by trituration with a syringe. One half of the faecal material was held on ice until use to minimise microbial replication and maintain viability of putative aetiological agents, including SFB (untreated faeces). The other half of the material was inactivated by autoclaving at $121^{\circ} \mathrm{C}$ for 20 min (inactivated faeces).

Recipient fish, which had not been fed for the previous $48 \mathrm{~h}$ to empty the stomach, were anaesthetised individually using $80 \mathrm{mg} \mathrm{l}^{-1} \mathrm{MS}-222$, and a $100 \mu \mathrm{l}$ aliquot of faecal material was delivered to the pyloric stomach by oral gavage. This volume appeared appropriate for the fish size, based on a post-mortem trial before the start of the challenge. Sixty fish received untreated faeces (test fish) and were placed in $1 \mathrm{~m}$ flow-through tanks in 2 groups of 30 . Thirtysix fish received inactivated faeces (control fish) and were placed in a single $1 \mathrm{~m}$ tank. In addition, 2 groups of fish received either untreated faeces (D30 test fish, 30 individuals) or inactivated faeces (D30 control fish, 30 individuals). These 2 groups were held in separate $1 \mathrm{~m}$ tanks for $30 \mathrm{~d}$ before sampling.

\section{Confirmation of the presence of SFB in donor fish}

Samples of pyloric caeca were collected from a number of donor fish immediately after collection of faecal material and fixed for $24 \mathrm{~h}$ in $10 \%$ neutral buffered formalin (NBF) prior to processing and waxembedding using standard histological procedures. Tissue sections $(3 \mu \mathrm{m})$ were stained using H\&E and Gram Twort or modified McDonald's Gram stain (www.americanmastertech.com/gram_stain.htm). In addition, DNA was extracted from pooled, expressed faecal material using a QIAamp DNA Stool Mini kit (Qiagen) following the manufacturer's instructions, and using a $95^{\circ} \mathrm{C}$ incubation as recommended. Nested PCR was carried out on isolated DNA to test for SFB presence, using amplification conditions and primers as described by Del-Pozo et al. (2010b); briefly, reactions were carried out in $25 \mu \mathrm{l}$ reaction volumes using Biotaq ${ }^{\mathrm{TM}}$ (BIO-21040, Bioline) following the manufacturer's instructions with a final concentration of $1 \mu \mathrm{M}$ of the appropriate primer pair. Cycling parameters and primer sequences are given in Table 1.

The identity of the PCR product was confirmed by sequencing following agarose gel electrophoresis and cleaning of the excised product using a MinElute Gel Extraction kit (Qiagen). Sequencing was carried out by the DNA Sequencing and Services unit, Dundee, UK.

\section{Sample collection}

Samples were collected from recipient fish following euthanasia. At 1, 8, 13, 16, 20, and $23 \mathrm{~d}$ post-challenge (dpc), 9 fish of the untreated faeces group and 6 fish of the inactivated faeces group were sampled. Statistical analysis of previous challenge trials at MSS as well as power analysis based on estimates of RTGE incidence from published information suggested that these were the minimum numbers of test and control individuals in timed samples required for robust detection of differences between treatments. 
Table 1. Nested PCR conditions used for amplification of segmented filamentous bacteria (SFB) 16S rRNA gene

\begin{tabular}{|c|c|c|c|c|c|}
\hline \multirow{2}{*}{$\begin{array}{l}\text { Amplification } \\
\text { round }\end{array}$} & \multirow{2}{*}{$\begin{array}{l}\text { Primer } \\
\text { name }\end{array}$} & \multirow[t]{2}{*}{ Primer sequence $\left(5^{\prime}-3^{\prime}\right)$} & \multicolumn{3}{|c|}{ - Cycling parameters - } \\
\hline & & & Temp $\left({ }^{\circ} \mathrm{C}\right)$ & Time & Cycle \\
\hline \multirow{5}{*}{$\begin{array}{l}1^{\text {st }} \text { round } \\
(2.5 \mu \text { l template })\end{array}$} & $20 \mathrm{~F}$ & AGA GTT TGA TCA TGG CTC AG & 94 & $5 \mathrm{~min}$ & Initial denaturation \\
\hline & $1500 \mathrm{R}$ & GGT TAC CTT GTT ACG ACT T & 94 & $30 \mathrm{~s}$ & \\
\hline & & & 56 & $1 \mathrm{~min} 30 \mathrm{~s}$ & 35 cycles \\
\hline & & & 72 & $1 \mathrm{~min} 30 \mathrm{~s}$ & \\
\hline & & & 72 & 7 min & Final extension \\
\hline \multirow{5}{*}{$\begin{array}{l}2^{\text {nd }} \text { round } \\
(1 \mu \mathrm{l} \text { template })\end{array}$} & SFB779F & TGT GGG TTG TGA ATA ACA AT & 94 & $5 \mathrm{~min}$ & Initial denaturation \\
\hline & SFB1380R & GGT TAG CCC ACA GGT TTC GG & 94 & $30 \mathrm{~s}$ & \\
\hline & & & 58 & $1 \mathrm{~min}$ & 35 cycles \\
\hline & & & 72 & $1 \mathrm{~min}$ & \\
\hline & & & 72 & $7 \mathrm{~min}$ & Final extension \\
\hline
\end{tabular}

At $30 \mathrm{dpc}$, all fish from the D30 test and control fish groups were sampled. Average fish weight increased from 169 to $228 \mathrm{~g}$ over the period of sampling. Pyloric intestine and distal intestine samples were placed in $10 \% \mathrm{NBF}$ and fixed overnight. Pyloric caeca were also placed in $95 \%$ ethanol and stored at $-80^{\circ} \mathrm{C}$. Proximal intestine and kidney were placed in RNAlater and stored at $-80^{\circ} \mathrm{C}$ following $24 \mathrm{~h}$ incubation at $4^{\circ} \mathrm{C}$. The term proximal intestine is used to denote a section of tissue including the terminal 2 to 3 pyloric caeca and extending ca. $1 \mathrm{~cm}$ along the intestine. This section of the intestine was chosen for investigation of immune gene expression as it incorporated and was contiguous with the pyloric caeca, the site in which SFB consistently occur, in our experience. Also, a finding from earlier work (Ú. McCarthy unpubl.) suggested that greater modulation of immune gene expression might occur in proximal intestine of RTGE-affected fish compared to distal intestine.

\section{Sample processing and analysis}

Formalin-fixed tissue was processed, embedded, sectioned and stained, as described above. Microscopic examination was carried out to evaluate the presence and degree of changes in pyloric caeca and intestines. Relative frequencies of karyorrectic enterocytes in the pyloric caeca were estimated from counts at 400x magnification. Karyorrexis was classed as 'frequent' in individuals where 2 or more affected enterocytes were observed per field of view (FOV), i.e. portions of individual mucosal folds, counted in triplicate. Karyorrexis was classed as infrequent in individuals where affected cells were not observed, or were distributed only sporadically through the cross-section of single caeca, i.e. multi- ple entire mucosal folds. In the distal intestine, supranuclear absorptive vacuoles (SNV) of enterocytes were described as absent, evident or prominent. These values were used to develop semiquantitative categorical scales to enable statistical comparison. The DNA was extracted from pyloric caeca in ethanol using a QIAamp DNA Stool Mini kit (Qiagen) and nested PCR for SFB was carried out as described above. This extraction procedure was also used in attempts to isolate DNA from other bacteria observed in the distal intestine of some test fish. Samples in RNAlater were homogenised in RLT buffer (Qiagen) containing $0.1 \% \beta$-mercaptoethanol, using a $7 \mathrm{~mm}$ steel bead and shaking at $25 \mathrm{~Hz}$ for $2 \mathrm{~min}$ in a Tissue Lyzer (Qiagen). RNA was extracted from $10 \mathrm{mg}$ homogenate using an RNeasy Blood and Tissue kit (Qiagen) following the manufacturer's instructions. Extracted RNA was quantified using a NanoDrop spectrophotometer (NanoDrop Technologies), and $1 \mu \mathrm{g}$ RNA was reverse transcribed into cDNA using TaqMan ${ }^{\circledR}$ Reverse Transcription Reagents with oligodT primers (Life Technologies). Amplifications of IFN $\gamma$, IL-17A/F, IL-22, IL-1 $\beta$ and elongation factor $(E F-1 \alpha)$ were carried out in $10 \mu$ reaction volumes using LightCycler ${ }^{\circledR} 480$ SYBR Green I Master (Roche) mix, $0.5 \mu \mathrm{l}$ (final concentration $500 \mu \mathrm{M}$ ) each primer and $1 \mu \mathrm{l}$ template cDNA on the LightCycler ${ }^{\circledR}$ 480 Real-Time PCR System (Roche). Primer sequences are given in Table 2. The PCR program used for amplification was as follows: 1 cycle of $95^{\circ} \mathrm{C}$ for $5 \mathrm{~min}, 45$ cycles of $94^{\circ} \mathrm{C}$ for $30 \mathrm{~s}$, annealing at $55^{\circ} \mathrm{C}$ for $30 \mathrm{~s}$ and extension at $72^{\circ} \mathrm{C}$ for $30 \mathrm{~s}$. To ensure that only a single product was amplified, a melting curve for each PCR reaction was obtained as follows: $95^{\circ} \mathrm{C}$ for $5 \mathrm{~s}, 65^{\circ} \mathrm{C}$ for $1 \mathrm{~min}$ and ramping to $97^{\circ} \mathrm{C}\left(0.11^{\circ} \mathrm{s}^{-1}\right.$, 5 acquisitions degree ${ }^{-1}$ ). Elongation factor was found to be stably expressed between test and control tissues during the duration of the challenge and was 
Table 2. Sequences of primers used in this study for cytokine gene expression

\begin{tabular}{|lllcl|}
\hline Gene & Forward primer $\left(5^{\prime}\right.$ to $\left.3^{\prime}\right)$ & Reverse primer (5' to $\left.3^{\prime}\right)$ & Accession no. & Source \\
\hline EF-1 $\alpha$ & CAAGGATATCCGTCGTGGCA & ACAGCGAAACGACCAAGAGG & AF498320 & Husain et al. (2012) \\
IL-1 $\beta$ & GCTGGAGAGTGCTGTGGAAGAACATATAG & CCTGGAGCATCATGGCGTG & AJ223954 & Husain et al. (2012) \\
IFN- $\gamma$ & CAAACTGAAAGTCCACTATAAGATCTCCA & TCCTGAATTTCCCCTTGACATATTT & AJ616215 & Zou et al. (2005) \\
IL-17A/F2 & CGTGTCGAAGTACCTGGTTGTGT & GGTTCTCCACTGTAGTGCTTTCCA & AJ580842 & Monte et al. (2013) \\
IL-22 & GAAGGAACACGGCTGTGCTATTAAAC & GATCTAGGCGTGCACACAGAAGTC & AM748538 & Monte et al. (2011) \\
\hline
\end{tabular}

used as the reference gene. For each primer pair, efficiency of amplification was calculated using standards (1/10 and 1/5 dilutions of cDNA) which were included on each plate, in triplicate. Using the efficiency information for each gene, the gene expression level (crossing point, $\mathrm{Cp}$ ) of each sample was then normalised to that of EF-1 $\alpha$ for the same sample (Pfaffl 2001). Extraction controls and controls containing no template were included in each reaction. The primers for real-time PCR analysis were designed so that at least 1 of the primers for each specific gene was across an intron, and it has been confirmed that they can only amplify from cDNA under our PCR conditions.

\section{Statistical analysis}

The presence of SFB (detected by PCR as well as observed in histological sections) and of other bacteria (histological sections only) within the gut was measured as a binomial response of presence or absence. The control and treatment groups were compared using a Fisher's exact test (StatXact v10.1). Statistical analysis of histological changes observed in the pyloric caeca and distal intestine between 1 and 23 dpc was not carried out, but the presence of frequent karyorrectic enterocytes in the pyloric caeca of D30 fish was measured as a binomial response and compared using a Fisher's exact test. Changes in SNV of D30 fish (response variables), measured on a categorical scale, were modelled by comparing the treatment and control group using Wilcoxon-Mann-Whitney tests for ordered categorical data using StatXact (v10.1).

Normalised cytokine gene expression values were $\log _{10}$ transformed, and differences between test and control fish were analysed in Minitab 15 using a 2sample $t$-test and allowing for unequal variances. The significance level was set at $p<0.05$. For the purposes of illustrating the data from 1 to $23 \mathrm{dpc}$ (see Fig. 3A), the method of Collet et al. (2015) was used. Briefly, using the mean and standard deviation of the log expression values for the control group, an 'envelope' was established with limits estimated from the 95 percentile interval (PI), within which the majority of expression values for fish exposed to inactivated faeces occur. Expression values for the experimental group outside this envelope then represent a possible response to challenge with untreated faeces. A difference in response between the 2 groups is regarded as statistically significant if the p-value for an increase in the proportion of experimental group expression values outside the PI limits relative to the control group is $\leq 0.05$, as determined using a 1-tailed Fisher's exact test. Analyses were performed using the R statistical environment (version 3.1.2; R Core Team 2014) and supplementary R-packages VGAM (version 0.9-6; Yee 2010).

\section{RESULTS}

\section{Presence of SFB}

The presence of SFB in the pyloric caeca of donor fish was confirmed microscopically, and presence in the faecal material used as challenge inoculum was confirmed by nested PCR.

At 1 dpc, a single test fish was positive for SFB using nested PCR, and numerous SFB were observed associated with necrotic cells and debris in the lumen of the pyloric caeca. The presence of SFB in the pyloric caeca of recipient fish given untreated faeces was detected by nested PCR in 3 of 9 test fish at $23 \mathrm{dpc}$ (33\% of test fish at this time point) and in 4 of 30 test fish at $30 \mathrm{dpc}(13 \%$; Fig. 1).

Numerous SFB, closely associated with enterocytes (i.e. apparently colonising the epithelium), were visible in histological sections of pyloric caeca from these fish (Fig. 2A). No SFB were detected in pyloric caeca of any fish receiving inactivated faeces either by microscopic examination or by nested PCR. In the recipient population, a significant difference in SFB presence was found between control and test fish $(\mathrm{p}=0.008)$. 


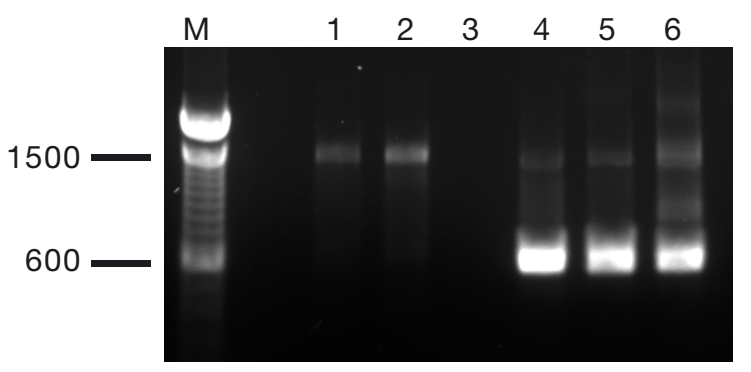

Fig. 1. Products of segmented filamentous bacteria (SFB)specific nested PCR in rainbow trout Oncorhynchus mykiss. DNA extracted from the pyloric caeca was used as template, and identity of PCR products (ca. $600 \mathrm{bp}$ ) was confirmed by sequencing as trout SFB 16S rRNA (rrs) DNA. SFB DNA was not amplified from any control fish or from negative control reactions (not all results are shown). Lanes 1 and 2 are amplification products from control fish; lanes 4,5 and 6 are products from fish in which SFB were observed in sections of pyloric caeca; and Lane 3 is a no-template control. M: $100 \mathrm{bp}$ ladder (LifeTechnologies). The positions of the 1500 and $600 \mathrm{bp}$ bands are indicated
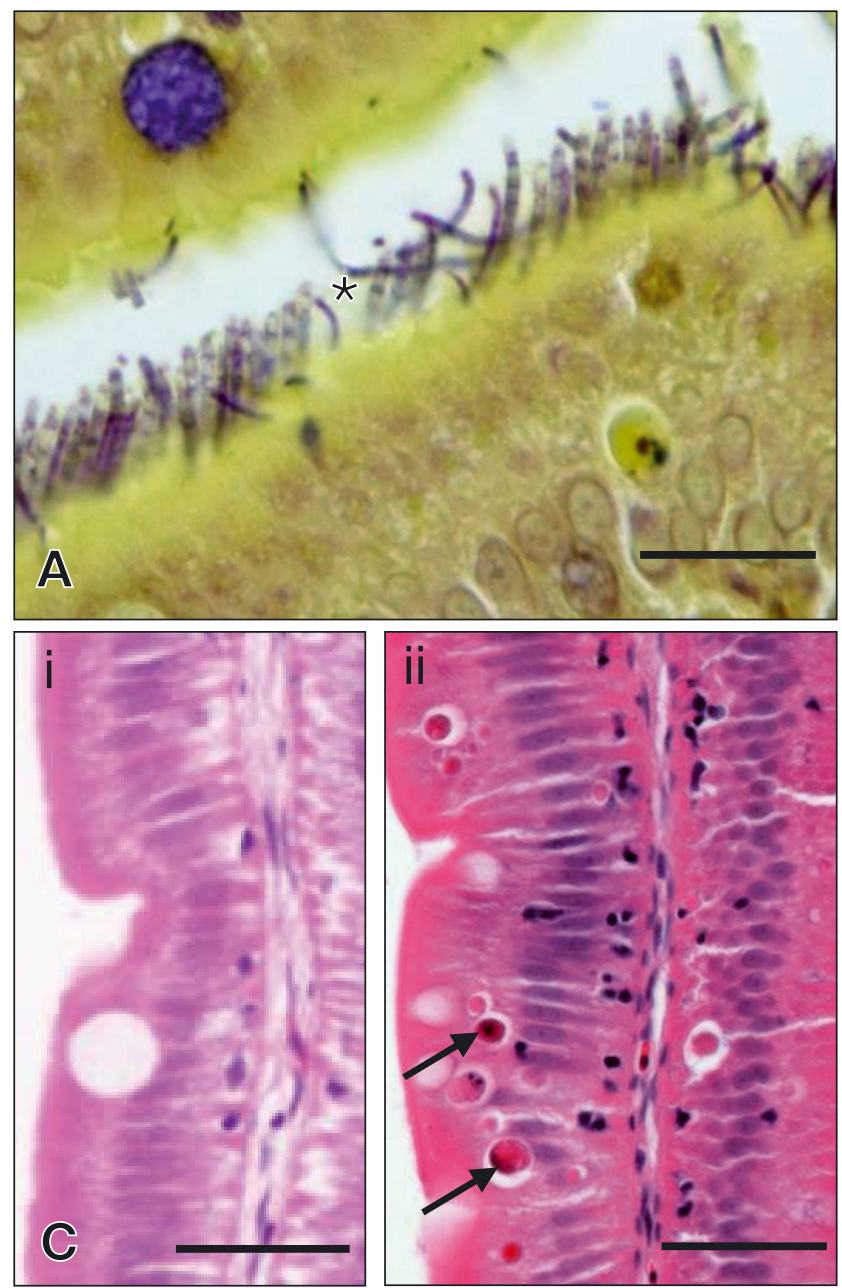

\section{Presence of other bacteria}

At $1 \mathrm{dpc}$ in test fish, large numbers of rodshaped bacteria were observed associated with the intestinal contents, particularly in the distal intestine (6/8 fish with contents present, not shown). They were not observed at $8 \mathrm{dpc}$ but were observed again at $13 \mathrm{dpc}$ in $4 / 8$ test fish with intestinal contents present, and at $23 \mathrm{dpc}$ in 1/9 fish (Table 3). Between 16 and $23 \mathrm{dpc}$, colonies of Gram-negative cocci were visible in 11/21 test fish where intestinal contents were present, often in close contact with the epithelial cell surface of the distal intestine (Fig. 2B). At $30 \mathrm{dpc}$, cocci were observed in 14/28 test fish. Attempts to isolate DNA and identify these cocci by amplification and sequencing of rrs DNA were unsuccessful. No bacteria were observed at any time in the intestine of any control fish.
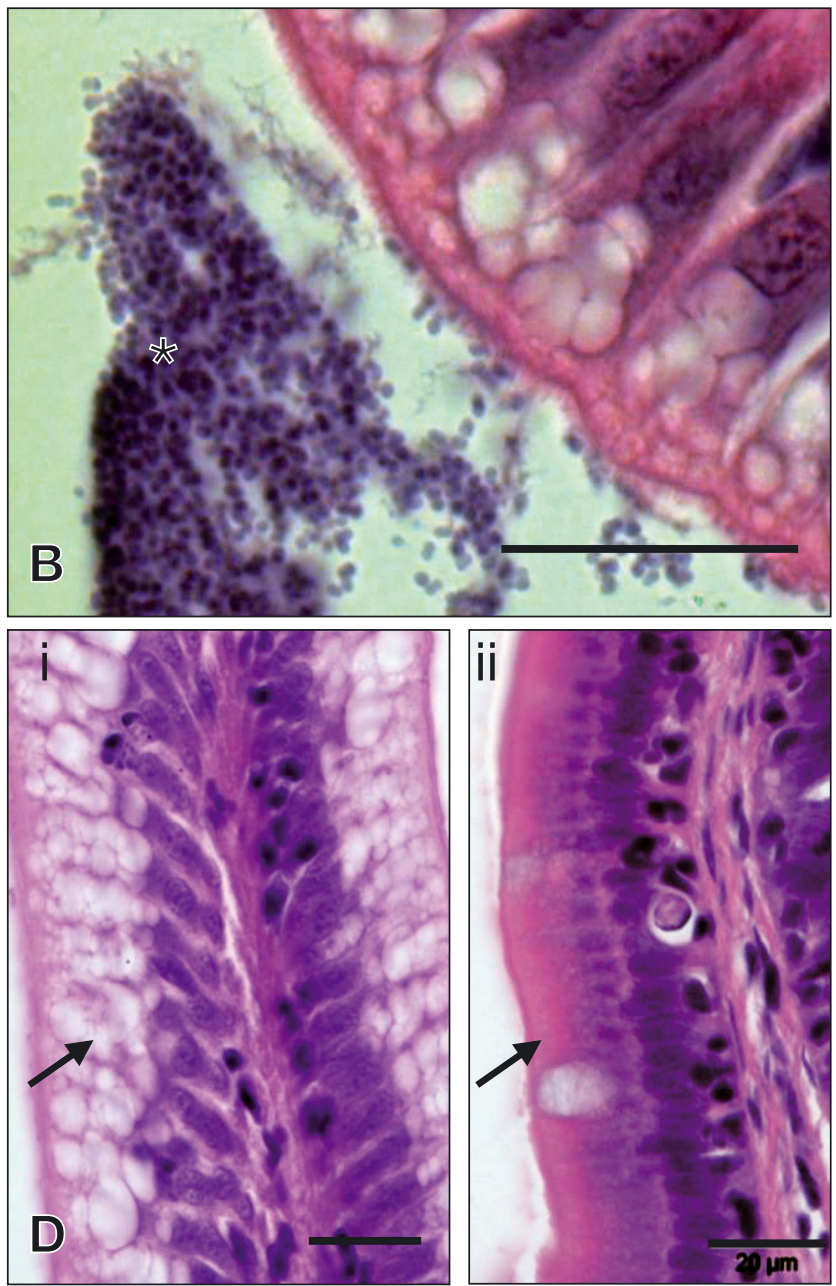

Fig. 2. Pyloric caecum and intestine of rainbow trout Oncorhynchus mykiss at $30 \mathrm{~d}$ following administration of untreated faeces from moribund rainbow trout gastroenteritis (RTGE)-positive fish. (A) Numerous segmented filamentous bacteria ( ${ }^{*}$ ) associated with luminal surface of enterocytes in pyloric caecum; modified McDonald's Gram stain, bar $=20 \mu \mathrm{m}$. (B) Mass of Gramnegative cocci $\left(^{*}\right)$ in close association with the epithelium of the distal intestine, H\&E, bar $=20 \mu m$. (C) Mucosal epithelium from pyloric caecum of fish with infrequent (i) or numerous (ii) karyorrectic enterocytes (arrows), H\&E, bar $=50 \mu \mathrm{m}$. (D) Prominent (i) and reduced (ii) supranuclear vacuoles (arrows) in the enterocytes of the distal intestine, H\&E, bar $=20 \mu \mathrm{m}$ 
Table 3. Intestinal changes in rainbow trout Oncorhynchus mykiss post-challenge with untreated faeces (test fish) or heat-inactivated faeces (control fish) at 1 to $23 \mathrm{~d}$ post challenge. The number of affected fish in each group is shown: test fish $\mathrm{n}=9$, control fish $\mathrm{n}=6$, except where indicated by the superscript. SFB: presence of segmented filamentous bacteria; frequent karyorrexis: $>2$ affected enterocytes per field of view at $400 \times$ magnification; SNV: enterocyte supranuclear vacuoles

\begin{tabular}{|c|c|c|c|c|c|}
\hline \multirow{2}{*}{$\begin{array}{l}\text { Days post } \\
\text { challenge } \\
\text { (fish group) }\end{array}$} & \multicolumn{3}{|c|}{${ }_{-}$Pyloric caeca -} & \multicolumn{2}{|c|}{ _ Distal intestine } \\
\hline & SFB & $\begin{array}{c}\text { Frequent } \\
\text { karyorrexis }\end{array}$ & $\begin{array}{l}\text { Other } \\
\text { bacteria } \\
\text { present }\end{array}$ & $\begin{array}{c}\text { Absence } \\
\text { of SNV }\end{array}$ & $\begin{array}{l}\text { Other } \\
\text { bacteria } \\
\text { present }\end{array}$ \\
\hline \multicolumn{6}{|l|}{1} \\
\hline Test & 1 & 9 & (Rods) 4 & $2^{8}$ & (Rods) $6^{8}$ \\
\hline Control & 0 & 6 & - & 0 & - \\
\hline \multicolumn{6}{|l|}{8} \\
\hline Test & 0 & 0 & - & 0 & - \\
\hline Control & 0 & 0 & - & 0 & - \\
\hline \multicolumn{6}{|l|}{13} \\
\hline Test & 0 & 0 & - & $0^{8}$ & (Rods) 4 (Cocci) $1^{8}$ \\
\hline Control & 0 & 1 & - & 0 & - \\
\hline \multicolumn{6}{|l|}{16} \\
\hline Test & 0 & 1 & - & 0 & (Cocci) $2^{6}$ \\
\hline Control & 0 & 0 & - & 0 & - \\
\hline \multicolumn{6}{|l|}{20} \\
\hline Test & 0 & 4 & - & 0 & (Cocci) 6 \\
\hline Control & 0 & 2 & - & 0 & - \\
\hline \multicolumn{6}{|l|}{23} \\
\hline Test & 3 & 3 & (Cocci) 2 & $2^{7}$ & (Rods) 1 (Cocci) $2^{7}$ \\
\hline Control & 0 & 3 & - & 0 & - \\
\hline
\end{tabular}

\section{Gross pathological changes}

Prior to $23 \mathrm{dpc}$, no significant or clearly diagnostic changes were observed, although yellow faeces or splenomegaly were noted in a few individuals from both test and control groups. At $23 \mathrm{dpc}$, a single fish in the test group exhibited a yellow mucus plug in the terminal portion of the intestine accompanied by mild congestion. At $30 \mathrm{dpc}$, congestion of the gut or the presence of yellow gut contents was observed in 9/30 test fish. Mild congestion and yellow gut contents were observed in 2/30 control fish.

\section{Enterocyte changes on Days 1 to 23 post-challenge}

At $1 \mathrm{dpc}$, karyorrectic enterocytes were very frequent (on average $>5$ per FOV, Fig. 2C) in both test and control fish. In the distal intestine, SNV were absent in 2/9 fish (Fig. 2D) and goblet cells were conspicuous. At 8, 13 and $16 \mathrm{dpc}$, in both test and control fish, karyorrexis was infrequently observed in the pyloric caeca (generally fewer than 5 affected cells in a cross-section of caecum), and SNV were evident- very prominent in the distal intestine (Fig. 2D). At 20 and $23 \mathrm{dpc}$, frequent karyorrexis was more prevalent in the pyloric caeca of both test and control fish and, at $23 \mathrm{dpc}$, SNV were absent in the distal intestine of 2/7 test fish (samples from 2 fish were lost during processing). Results are summarised in Table 3.

\section{Enterocyte changes on Day 30 post- challenge}

In the pyloric caeca of D30 fish, frequent karyorectic enterocytes were observed in 18/29 test fish compared with $3 / 30$ of controls. In the distal intestine, SNV were absent in $7 / 28$ of test fish compared with $1 / 27$ of controls. The pyloric caeca sample from 1 test fish and distal intestine from 2 test and 3 control fish were lost in processing. The results for D30 fish are summarised in Table 4.

Statistical analysis of results for D30 fish showed that both bacterial presence and nuclear fragmentation in test fish were significantly higher than in control fish (Fisher's exact 1-sided test, p < 0.01 and $\mathrm{p}<0.001$, respectively). In contrast, SNV levels were significantly higher in control fish than in test fish $(\mathrm{p}<0.001)$.

\section{Gene expression}

Expression of IFN- $\gamma$ in the proximal intestine of test fish increased post-challenge and was significantly higher than in control fish at all time points from 8 to $23 \mathrm{dpc}$, but no difference was found at $30 \mathrm{dpc}$. From 1 to $23 \mathrm{dpc}$, no difference in IL-17A/F expression was found between test and control groups, but a significant difference was found in IL-22 expression, largely due to raised expression in some individual test fish (Fig. 3A). Expression of both IL-17A/F and IL-22 was significantly higher in the D30 test fish compared with controls ( $p<0.01$ and $p<0.001$, respectively). No significant difference was detected between test and control fish in expression of IL-1 $\beta$ at any sampling point (Fig. 3B). Likewise, no difference was found between test and control fish in IL-1 $\beta$ expression in kidney (not shown). 
Table 4. Intestinal changes in rainbow trout Oncorhynchus mykiss observed at $30 \mathrm{~d}$ post-challenge with heat-inactivated faeces (control fish, $\mathrm{n}=30$ ) or untreated faeces (test fish, $\mathrm{n}=30$ ). SFB: segmented filamentous bacteria associated with enterocytes in the pyloric caeca; P: present; A: absent; Karyo: karyorrectic enterocytes in the pyloric caeca; F: frequent ( $\geq 2$ affected cells per field of view at $400 \times$ ); I: infrequent; Cocci: Gram-negative cocci in the intestinal lumen; SNV: prominence of supranuclear vacuoles in the enterocytes of the distal intestine $(0=$ none, $1=$ evident, $2=$ prominent, 3 = very prominent), ns: no sample

\begin{tabular}{|c|c|c|c|c|c|c|c|}
\hline \multicolumn{4}{|c|}{ Control fish -} & \multicolumn{4}{|c|}{ - Test fish- } \\
\hline SFB & Karyo & Cocci & SNV & SFB & Karyo & Cocci & SNV \\
\hline A & I & A & 0 & $\mathrm{P}$ & F & $\mathrm{P}$ & 0 \\
\hline $\mathrm{A}$ & I & A & 1 & $\mathrm{P}$ & F & $\mathrm{P}$ & 0 \\
\hline $\mathrm{A}$ & I & A & 1 & $\mathrm{~A}$ & F & $\mathrm{P}$ & 0 \\
\hline A & I & A & 1 & A & $\mathrm{F}$ & $\mathrm{P}$ & 0 \\
\hline A & $\mathrm{F}$ & A & 2 & $\mathrm{~A}$ & $\mathrm{~F}$ & $\mathrm{P}$ & 0 \\
\hline $\mathrm{A}$ & I & A & 2 & $\mathrm{P}$ & $\mathrm{F}$ & $\mathrm{A}$ & 0 \\
\hline A & I & A & 2 & $\mathrm{~A}$ & $\mathrm{~F}$ & $\mathrm{~A}$ & 0 \\
\hline $\mathrm{A}$ & I & A & 2 & $\mathrm{P}$ & I & $\mathrm{A}$ & 0 \\
\hline A & I & A & 2 & $\mathrm{~A}$ & I & $\mathrm{A}$ & 0 \\
\hline $\mathrm{A}$ & F & A & 3 & $\mathrm{~A}$ & F & $\mathrm{P}$ & 1 \\
\hline $\mathrm{A}$ & F & A & 3 & $\mathrm{~A}$ & F & $\mathrm{P}$ & 1 \\
\hline A & I & A & 3 & $\mathrm{~A}$ & $\mathrm{~F}$ & $\mathrm{P}$ & 1 \\
\hline $\mathrm{A}$ & I & A & 3 & A & I & $\mathrm{P}$ & 1 \\
\hline A & I & A & 3 & A & I & $\mathrm{P}$ & 1 \\
\hline A & I & A & 3 & A & I & $\mathrm{P}$ & 1 \\
\hline A & I & A & 3 & $\mathrm{~A}$ & I & $\mathrm{P}$ & 1 \\
\hline A & I & A & 3 & A & F & A & 1 \\
\hline $\mathrm{A}$ & I & A & 3 & A & F & $\mathrm{A}$ & 1 \\
\hline $\mathrm{A}$ & I & A & 3 & A & I & $\mathrm{A}$ & 1 \\
\hline $\mathrm{A}$ & I & A & 3 & A & $\mathrm{F}$ & $\mathrm{P}$ & 2 \\
\hline $\mathrm{A}$ & I & A & 3 & A & I & $\mathrm{P}$ & 2 \\
\hline A & I & A & 3 & A & $\mathrm{F}$ & A & 2 \\
\hline $\mathrm{A}$ & I & A & 3 & A & $\mathrm{F}$ & $\mathrm{P}$ & 3 \\
\hline A & I & A & 3 & A & $\mathrm{F}$ & A & 3 \\
\hline A & I & A & 3 & $\mathrm{~A}$ & $\mathrm{~F}$ & $\mathrm{~A}$ & 3 \\
\hline A & I & A & 3 & $\mathrm{~A}$ & $\mathrm{~F}$ & $\mathrm{~A}$ & 3 \\
\hline A & I & A & 3 & A & I & A & 3 \\
\hline $\mathrm{A}$ & I & $\mathrm{ns}$ & $\mathrm{ns}$ & A & I & A & 3 \\
\hline A & I & $\mathrm{ns}$ & $\mathrm{ns}$ & $\mathrm{ns}$ & I & ns & ns \\
\hline A & I & $\mathrm{ns}$ & $\mathrm{ns}$ & $\mathrm{ns}$ & ns & ns & $\mathrm{ns}$ \\
\hline
\end{tabular}

\section{DISCUSSION}

The aim of this work was to determine whether SFB could be transferred directly between rainbow trout by artificial challenge, as a first step towards developing a challenge model for investigating the aetiology of RTGE. Enterocyte-associated SFB were detected in 7 out of 39 recipient fish at least $23 \mathrm{~d}$ after gavage with untreated faeces from SFB-positive fish. At this level of incidence, there is $>99 \%$ chance of 1 or more individuals being SFB-positive among 66 control fish held under identical conditions, if SFB were present throughout the population of recipient fish. This suggests that the administration of SFB- positive faecal material resulted in the colonisation by SFB in the pyloric caeca of apparently naive fish, and that the 'factor' required for SFB growth was inactivated by autoclaving the faeces. This factor may simply be viable SFB. Alternatively, a heatlabile component or other agent may be required for SFB growth; in order to test this, it will be necessary to administer purified SFB and, to that end, moderate heat or alcohol treatment of faecal material (Klaasen et al. 1991, Gaboriau-Routhiau et al. 2009) or anaerobic incubation (Ericsson et al. 2015) should be investigated for future studies. Meanwhile, the absence of SFB in control recipient fish indicates that higher feed rates and elevated temperatures alone were not sufficient to stimulate the growth of SFB within the same time frame.

In the pyloric caeca, the most obvious pathological change was increased frequency of karyorrectic enterocytes. These are considered to be apoptotic cells, which are observed occasionally in apparently healthy intestinal epithelium but which can be more frequent in enteritis, e.g. 'McKnight cells' in salmonids with acute infectious pancreatic necrosis (Roberts \& Pearson 2005). In the distal intestine, the most obvious and defined pathological change, present in some test fish, was the absence of supranuclear vacuoles. Loss of SNV in the distal intestine of fish has been described in soybean meal (SBM) enteritis and is thought to result from disturbance to the process of endocytosis by components in the diet (Baeverfjord \& Krogdahl 1996, Bakke McKellep et al. 2007, Urán et al. 2008, 2009). In the present case, this change may indicate that an inflammatory immune response is occurring (Sahlmann et al. 2015). On the day following challenge, pathological changes were observed in the pyloric caeca and distal intestine of both test and control fish. However, these were no longer apparent in samples taken on Day 8, and further changes were not apparent in test fish until later in the challenge. Although congestion of the lamina propria and detachment of enterocytes were present in some SFB-positive fish, clear development of certain gross clinical signs of RTGE, namely a swollen appearance, lighter colouration and striping of flanks (Del-Pozo et al. 2010c), was not achieved within $30 \mathrm{~d}$ following administration of inactivated faeces. Relatively minor and non-specific gross changes (congested intestine, yellow or watery gut content) were noted in fish 23 and $30 \mathrm{~d}$ after receiving untreated faeces, but these changes were not present only in SFB-positive fish. It may be that longer incubation post-exposure was required for the full development of clinical RTGE under the aquarium conditions. 

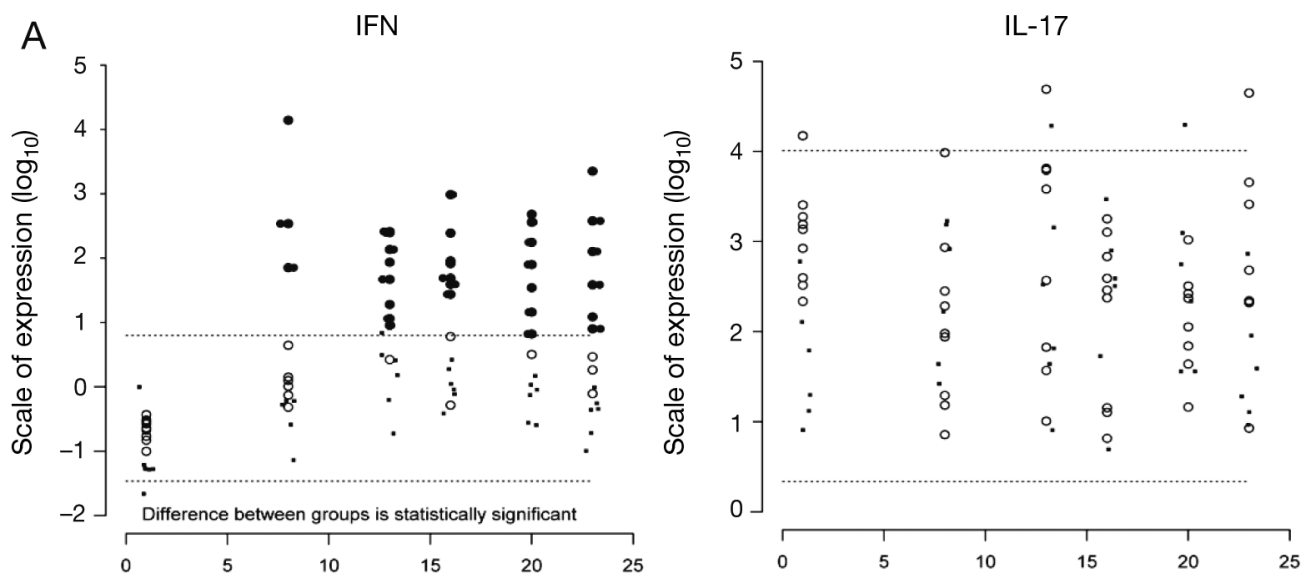

IL-22
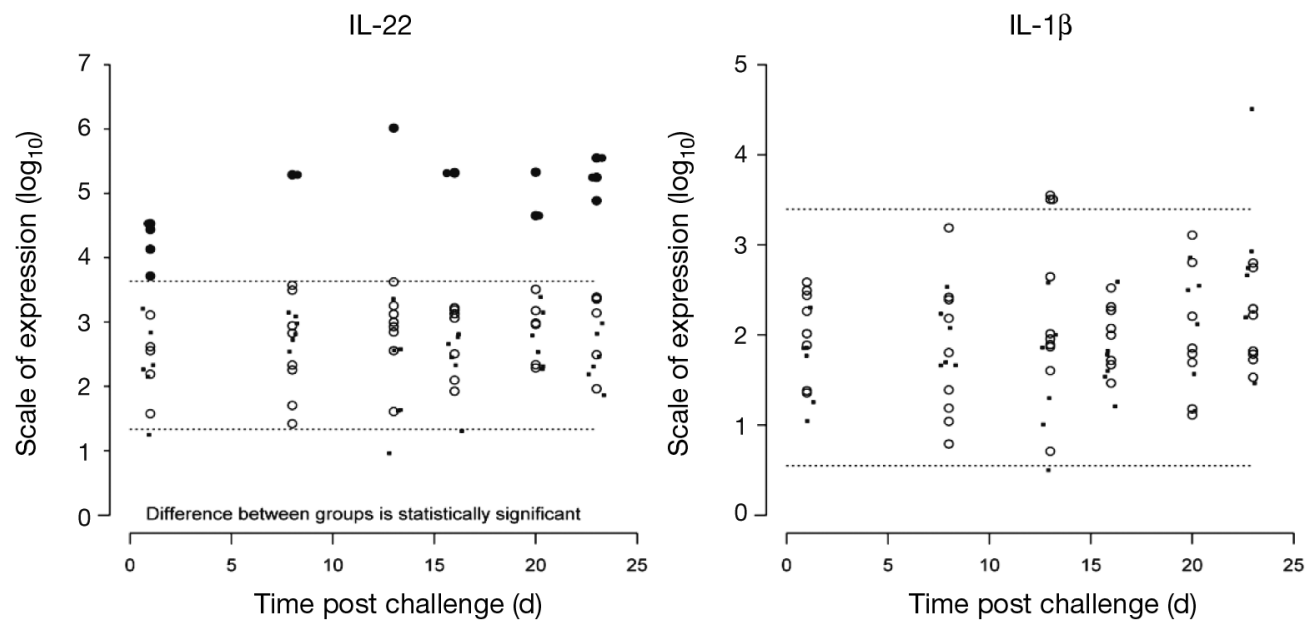

Fig. 3. Cytokine gene expression in the proximal intestine of individual rainbow trout Oncorhynchus mykiss. (A) Relative expression of IFN $\gamma$, IL-17A/F, IL-22 and IL-1 $\beta$ at 1 to $23 \mathrm{~d}$ post-challenge (dpc) in fish exposed to untreated faeces (test fish, $\mathrm{n}=9$ ) relative to fish exposed to heat-inactivated faeces (control fish, $\mathrm{n}=6$ ) by oral gavage. Dots represent control group values and the dashed lines are the predicted 2.5 and 97.5 percentiles around these. Solid (open) circles represent test group values which are categorised as responding (not responding). Values around the fixed time points of 1, 8, 13, 16, 20 and $23 \mathrm{~d}$ have been horizontally jittered to improve visualisation. Arbitrary values on the $y$-axis indicate the relative $\log _{10}$ response patterns. The difference between the control group and the test group is statistically significant for IFN- $\gamma$ and IL-22. (B) At $30 \mathrm{dpc}$, closed circles

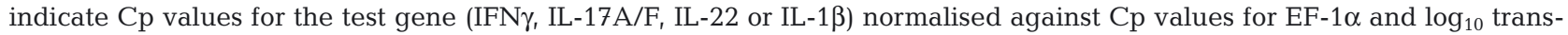
formed: test fish $n=30$, control fish $n=30$. Values have been horizontally jittered to improve visualisation. The mean is indicated by a horizontal bar. The difference between the control fish and test fish is statistically significant ( $\left.{ }^{*}\right)$ for IL-17 and IL-22

Alternatively, given that short-term withholding of feed is used as a management tool by industry to alleviate the condition (both in the UK and mainland Europe; direct communication with industry personnel), the short starve period in preparation for the aquarium challenge may have reduced susceptibility to the disease. On a commercial production site where RTGE outbreaks occur annually, the disease was diagnosed in fish from the same batch as these experimental fish in early August (direct communication with company personnel), around the same time as the aquarium challenge was carried out. Fish used in the aquarium challenge weighed more than their commercially reared counterparts (169 g versus $75 \mathrm{~g}$ ), which again suggests that higher feeding rate alone is not sufficient to trigger RTGE. However, the commercially reared fish experienced 2 temperature spikes in the month before the outbreak, with temperatures reaching over $21^{\circ} \mathrm{C}$, and these more extreme temperatures and fluctuations may have caused additional stress contributing to RTGE onset.

The faecal material used for the inoculum will have contained numerous microorganisms of unknown pathogenicity, but full identification of the faecal microbiota using culture-independent methods was beyond the scope of this work. No attempt was made 

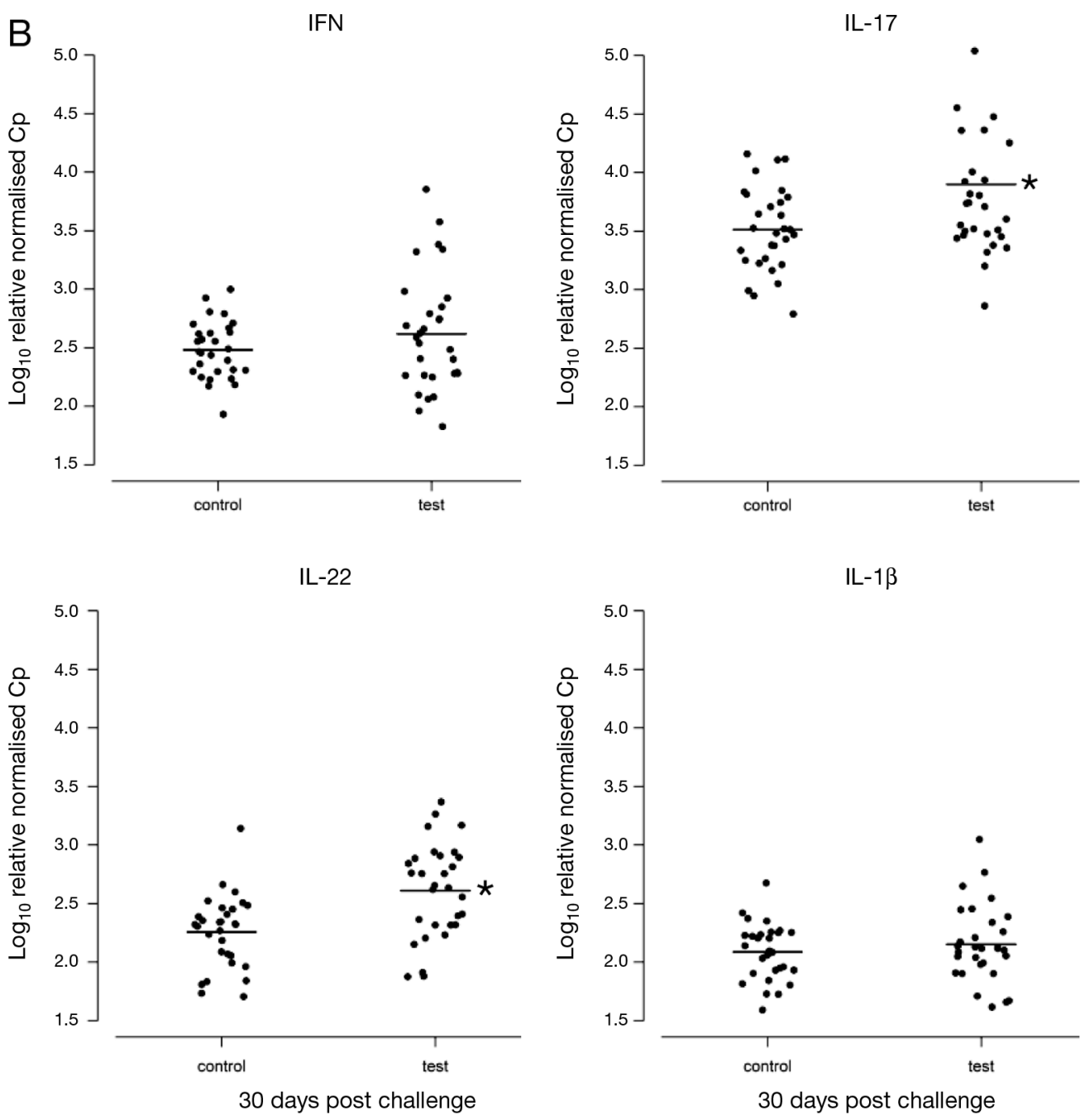

Fig. 3 (continued)

to culture organisms from the faecal material, as many members of the microbiota are not readily cultivable, if at all, and even if an organism were isolated, as with SFB this would not necessarily confirm its role in RTGE. Perhaps interestingly, Koopman et al. (1987) reported that during the first days of ileal colonisation by SFB in mice, the SFB themselves were subcolonised by small rod-shaped bacteria. Attempts to isolate and amplify DNA of the Gramnegative coccus observed in the tissue sections were unsuccessful, and no clear match was found between partial sequences obtained from DNA isolated from distal intestine samples and isolates on GenBank (92\% identity over 828 bases). It is possible that some of the gross or histological changes observed were due to pathogens unconnected with RTGE; for instance, the unidentified Gram-negative coccus may have contributed to the enterocyte pathology, although the presence of these organisms and the pathological changes were not always coincidental. Although mixed bacterial cultures have been obtained from intestinal contents, previous histological reports on the intestine of clinically-affected RTGE fish do not mention the presence of bacteria other than SFB (Michel et al. 2002, Branson 2003, Del-Pozo et al. 2010c). Nevertheless, the presence of SFB in RTGE-affected fish does not necessarily mean that they are the aetiological agent.

In an experimental model of necrotic enteritis in chickens, challenge with Clostridium perfringens resulted in the induction of SFB growth and the suppression of $C$. perfringens in the gut (Stanley et al. 2014). In germ-free mice, colonisation with SFB induced Th17 accumulation in the intestinal lamina propria and reduced inflammation and colonisation by the pathogen Citrobacter rodentium (Ivanov et al. 
2009). Colonisation by SFB results in increased expression of IL-17, IL-22 and IFN- $\gamma$ in mice (Gaboriau-Routhiau et al. 2009, Ivanov et al. 2009). The upregulation of IFN- $\gamma$, IL-17A/F and IL-22 in test fish after intubation with SFB-containing faeces is consistent with this, although the increased expression in individual fish did not always correspond with the ability to detect SFB in their intestine. It is also possible that increased expression following administration of untreated faeces was occurring in reaction to the other observed bacteria. Both IL-17 and IL-22 are important in mucosal immunity, inducing the expression of antimicrobial peptides by epithelial cells, upregulating mucus production by goblet cells and maintaining the integrity of tight junctions (Monte et al. 2011, 2013, Sawa et al. 2011, Rutz et al. 2013). IL17 plays a dual role, both providing defence against pathogens and being implicated in the pathophysiology of conditions such as inflammatory bowel disease (Fujino et al. 2003, Ishigame et al. 2009, Leppkes et al. 2009). Likewise, IFN- $\gamma$ can mediate both inflammatory and anti-inflammatory responses (Do et al. 2014). Careful balance of these cytokines is essential to avoid excessive inflammatory response and the development of tissue pathology (Jin et al. 2012, Rutz et al. 2013, Nau et al. 2014). The microbiota regulate production of IFN- $\gamma$, IL-17 and IL-22, and thus a finely controlled equilibrium between host defence and the microbiota is necessary (GaboriauRouthiau et al. 2009, Sawa et al. 2011). Given the interaction between the microbiota and intestinal immunity and in particular, the role of SFB in mucosal Th17 responses, it seems possible that in RTGE an environmental or dietary stress has resulted in disequilibrium and an increase in SFB may be a secondary outcome, induced in an attempt to reestablish homeostasis.

The present study has shown that it is possible to produce conditions experimentally which are permissive to SFB growth in artificially challenged rainbow trout. Furthermore, the apparent ability of transmissable SFB to survive the transport of donor fish holds some hope that the organisms could withstand further purification; the capacity to deliver SFB as a pure inoculum would simplify analysis of their effects on the intestine and role in RTGE. The detection of enterocyte-associated SFB as well as pathological changes consistent with early signs of RTGE, at 23 to $30 \mathrm{~d}$ after gavage, is in agreement with the timing of disease development reported by del-Pozo et al. (2010a) and suggests that this is an appropriate timescale for future challenge studies. However, even if the role of SFB in RTGE is elucidated, man- agement measures will still be required to prevent disease occurrence. Given the observation from the UK and European trout industries (direct communication with industry personnel) that starvation can help to reduce RTGE mortality, the effect of shortterm starvation on the fish intestine (Krogdahl \& Bakke-McKellep 2005, Baumgarner et al. 2013, Liu et al. 2013, Li et al. 2014) should be further investigated in RTGE. It would also be helpful for development of disease management tools to investigate historical farm records of environmental conditions and feeding strategies, including details of fast periods, in connection with RTGE onset.

Acknowledgements. We acknowledge the invaluable contribution of Scottish trout farmers to this work by providing fish and feed. Prof. Chris Secombes and Dr. Tiehui Wang, University of Aberdeen, generously provided a number of PCR primers developed in their laboratory. At Marine Scotland Science, Dr. Malcolm Hall provided the statistical support essential for Home Office approval of aquarium experiments, and Zoe Allcock assisted with statistical analysis of results. Kirsty Donald provided technical support. We thank Dr. Catherine Collins for useful comments on the manuscript.

\section{LITERATURE CITED}

Baeverfjord G, Krogdahl A (1996) Development and regression of soybean meal induced enteritis in Atlantic salmon, Salmo salar L., distal intestine: a comparison with the intestines of fasted fish. J Fish Dis 19: 375-387

Bakke-McKellep AM, Koppang EO, Gunnes G, Sanden M, Hemre GI, Landsverk T, Krogdahl A (2007) Histological, digestive, metabolic, hormonal and some immune factor responses in Atlantic salmon, Salmo salar L., fed genetically modified soybeans. J Fish Dis 30:65-79

Baumgarner BL, Bharadwaj AS, Inerowicz D, Goodman AS, Brown PB (2013) Proteomic analysis of rainbow trout (Oncorhynchus mykiss) intestinal epithelia: Physiological acclimation to short-term starvation. Comp Biochem Physiol D Genomics Proteomics 8:58-64

Branson E (2003) Rainbow trout gastroenteritis (RTGE) first diagnosis in the UK. Fish Vet J 7:71-76

Chase DG, Erlandsen SL (1976) Evidence for a complex life cycle and endospore formation in the attached, filamentous, segmented bacterium from murine ileum. J Bacteriol 127:572-583

> Collet B, Urquhart K, Monte M, Collins M, Garcia Perez S, Secombes CJ, Hall M (2015) Individual monitoring of immune response in Atlantic salmon Salmo salar following experimental infection with infectious salmon anaemia virus (ISAV). PLoS ONE 10:e0137767

Davis CP, Savage DC (1974) Habitat, succession, attachment, and morphology of segmented, filamentous microbes indigenous to the murine gastrointestinal tract. Infect Immun 10:948-956

Del-Pozo J, Crumlish M, Ferguson HW, Turnbull JF (2009) A retrospective cross-sectional study on 'Candidatus 
arthromitus' associated rainbow trout gastroenteritis (RTGE) in the UK. Aquaculture 290:22-27

> Del-Pozo J, Crumlish M, Ferguson HW, Green DM, Turnbull JF (2010a) A prospective longitudinal study of 'Candidatus arthromitus'-associated rainbow trout gastroenteritis in the UK. Prev Vet Med 94:289-300

> Del-Pozo J, Turnbull JF, Ferguson H, Crumlish M (2010b) A comparative molecular study of the presence of 'Candidatus arthromitus' in the digestive system of rainbow trout, Oncorhynchus mykiss (Walbaum), healthy and affected with rainbow trout gastroenteritis. J Fish Dis 33:241-250

> Del-Pozo J, Turnbull JF, Crumlish M, Ferguson HW (2010c) A study of gross, histological and blood biochemical changes in rainbow trout, Oncorhynchus mykiss (Walbaum), with rainbow trout gastroenteritis (RTGE). J Fish Dis 33:301-310

> Do JS, Asosingh K, Baldwin WM, Min B (2014) Cutting edge: IFN- $\gamma \mathrm{R}$ signaling in non- $\mathrm{T}$ cell targets regulates $\mathrm{T}$ cell-mediated intestinal inflammation through multiple mechanisms. J Immunol 192:2537-2541

Ericsson AC, Hagan CE, Davis DJ, Franklin CL (2014) Segmented filamentous bacteria: commensal microbes with potential effects on research. Comp Med 64:90-98

Ericsson AC, Turner G, Montoya L, Wolfe A and others (2015) Isolation of segmented filamentous bacteria from complex gut microbiota. Biotechniques 59:94-98

Fujino S, Andoh A, Bamba S, Ogawa A and others (2003) Increased expression of interleukin 17 in inflammatory bowel disease. Gut 52:65-70

Gaboriau-Routhiau V, Rakotobe S, Lecuyer E, Mulder I and others (2009) The key role of segmented filamentous bacteria in the coordinated maturation of gut helper $\mathrm{T}$ cell responses. Immunity 31:677-689

Goto Y, Panea C, Nakato G, Cebula A and others (2014) Segmented filamentous bacteria antigens presented by intestinal dendritic cells drive mucosal Th17 cell differentiation. Immunity 40:594-607

> Husain M, Bird S, van Zwieten R, Secombes CJ, Wang T

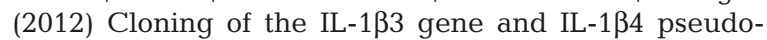
gene in salmonids uncovers a second type of IL-1 $\beta$ gene in teleost fish. Dev Comp Immunol 38:431-446

Ishigame H, Kakuta S, Nagai T, Kadoki M and others (2009) Differential roles of interleukin-17A and-17F in host defense against mucoepithelial bacterial infection and allergic responses. Immunity 30:108-119

> Ivanov II, Atarashi K, Manel N, Brodie EL and others (2009) Induction of intestinal Th17 cells by segmented filamentous bacteria. Cell 139:485-498

Jin Y, Lin Y, Lin L, Zheng C (2012) IL-17/IFN- $\gamma$ interactions regulate intestinal inflammation in TNBS-induced acute colitis. J Interferon Cytokine Res 32:548-556

Klaasen HLBM, Koopman JP, Vandenbrink ME, Vanwezel HPN, Beynen AC (1991) Mono-association of mice with non-cultivable, intestinal, segmented, filamentous bacteria. Arch Microbiol 156:148-151

> Klaasen HLBM, Koopman JP, Vandenbrink ME, Bakker $\mathrm{MH}$, Poelma FGJ, Beynen AC (1993a) Intestinal, segmented, filamentous bacteria in a wide-range of vertebrate species. Lab Anim 27:141-150

> Klaasen HL, Vanderheijden PJ, Stok W, Poelma FGJ and others (1993b) Apathogenic, intestinal, segmented, filamentous bacteria stimulate the mucosal immune-system of mice. Infect Immun 61:303-306

Koopman JP, Stadhouders AM, Kennis HM, De Boer H (1987) The attachment of filamentous segmented micro- organisms to the distal ileum wall of the mouse: a scanning- and transmission-electron-microscopy study. Lab Anim 21:48-52

Krogdahl Å, Bakke-McKellep AM (2005) Fasting and refeeding cause rapid changes in intestinal tissue mass and digestive enzyme capacities of Atlantic salmon (Salmo salar L.). Comp Biochem Physiol A Mol Integr Physiol 141:450-460

> Leppkes M, Becker C, Ivanov II, Hirth S and others (2009) ROR $\gamma$-expressing Th17 cells induce murine chronic intestinal inflammation via redundant effects of IL-17A and IL-17F. Gastroenterology 136:257-267

Li C, Beck BH, Peatman E (2014) Nutritional impacts on gene expression in the surface mucosa of blue catfish (Ictalurus furcatus). Dev Comp Immunol 44:226-234

Liu L, Li C, Su B, Beck BH, Peatman E (2013) Short-term feed deprivation alters immune status of surface mucosa in channel catfish (Ictalurus punctatus). PLoS ONE 8: e74581

> Michel C, Bernardet JF, Daniel P, Chilmonczyk S, Urdaci M, De Kinkelin P (2002) Clinical and aetiological aspects of a summer enteritic syndrome associated with the sporulating segmented filamentous bacterium 'Candidatus Arthromitus' in farmed rainbow trout, Oncorhynchus mykiss (Walbaum). J Fish Dis 25:533-543

Monte MM, Zou J, Wang T, Carrington A, Secombes CJ (2011) Cloning, expression analysis and bioactivity studies of rainbow trout (Oncorhynchus mykiss) interleukin22. Cytokine 55:62-73

Monte MM, Wang T, Holland JW, Zou J, Secombes CJ (2013) Cloning and characterization of rainbow trout interleukin-17A/F2 (IL-17A/F2) and IL-17 receptor A: expression during infection and bioactivity of recombinant IL-17A/F2. Infect Immun 81:340-353

Nau D, Altmayer N, Mattner J (2014) Mechanisms of innate lymphoid cell and natural killer $\mathrm{T}$ cell activation during mucosal inflammation. J Immunol Res 2014:546596

> Pfaffl MW (2001) A new mathematical model for relative quantification in real-time RT-PCR. Nucleic Acids Res 29:e45

R Core Team (2014) R: a language and environment for statistical computing. R Foundation for Statistical Computing, Vienna. www.r-project.org

Roberts RJ, Pearson MD (2005) Infectious pancreatic necrosis in Atlantic salmon, Salmo salar L. J Fish Dis 28: 383-390

Rutz S, Eidenschenk C, Ouyang W (2013) IL-22, not simply a Th17 cytokine. Immunol Rev 252:116-132

Sahlmann C, Gu J, Kortner TM, Lein I, Krogdahl Å, Bakke AM (2015) Ontogeny of the digestive system of Atlantic salmon (Salmo salar L.) and effects of soybean meal from start-feeding. PLoS ONE 10:e0124179

Sawa S, Lochner M, Satoh-Takayama N, Dulauroy S and others (2011) ROR gamma $t(+)$ innate lymphoid cells regulate intestinal homeostasis by integrating negative signals from the symbiotic microbiota. Nat Immunol 12: 320-326

Schnupf P, Gaboriau-Routhiau V, Gros M, Friedman R and others (2015) Growth and host interaction of mouse segmented filamentous bacteria in vitro. Nature 520:99-103

> Snel J, Heinen PP, Blok HJ, Carman RJ, Duncan AJ, Allen PC, Collins MD (1995) Comparison of 16S rRNA sequences of segmented filamentous bacteria isolated from mice, rats, and chickens and proposal of Candidatus Arthromitus. Int J Syst Bacteriol 45:780-782 
Stanley D, Wu SB, Rodgers N, Swick RA, Moore RJ (2014) Differential responses of cecal microbiota to fishmeal, Eimeria and Clostridium perfringens in a necrotic enteritis challenge model in chickens. PLoS ONE 9:e104739

Talham GL, Jiang HQ, Bos NA, Cebra JJ (1999) Segmented filamentous bacteria are potent stimuli of a physiologically normal state of the murine gut mucosal immune system. Infect Immun 67:1992-2000

Tannock GW, Miller JR, Savage DC (1984) Host specificity of filamentous, segmented microorganisms adherent to the small bowel epithelium in mice and rats. Appl Environ Microbiol 47:441-442

Thompson CL, Vier R, Mikaelyan A, Wienemann T, Brune A (2012) 'Candidatus Arthromitus' revised: segmented filamentous bacteria in arthropod guts are members of Lachnospiraceae. Environ Microbiol 14:1454-1465

Urán PA, Aydin R, Schrama JW, Verreth JAJ, Rombout JHWM (2008) Soybean meal-induced uptake block in Atlantic salmon Salmo salar distal enterocytes. J Fish Biol 73:2571-2579

Urán PA, Schrama JW, Rombout JHWM, Taverne-Thiele JJ, Obach A, Koppe W, Verreth JAJ (2009) Time-related

Editorial responsibility: Stephen Feist,

Weymouth, UK changes of the intestinal morphology of Atlantic salmon, Salmo salar L., at two different soybean meal inclusion levels. J Fish Dis 32:733-744

> Urdaci MC, Regnault B, Grimont PAD (2001) Identification by in situ hybridization of segmented filamentous bacteria in the intestine of diarrheic rainbow trout (Oncorhynchus mykiss). Res Microbiol 152:67-73

- Wu HJ, Ivanov II, Darce J, Hattori K and others (2010) Gutresiding segmented filamentous bacteria drive autoimmune arthritis via $\mathrm{T}$ helper 17 cells. Immunity 32: $815-827$

> Yee TW (2010) The VGAM package for categorical data analysis. J Stat Softw 32:1-34

Yin YS, Wang Y, Zhu LY, Liu W and others (2013) Comparative analysis of the distribution of segmented filamentous bacteria in humans, mice and chickens. ISME J 7 : 615-621

Zou J, Carrington A, Collet B, Dijkstra JM, Yoshiura Y, Bols N, Secombes C (2005) Identification and bioactivities of IFN-gamma in rainbow trout Oncorhynchus mykiss: the first Th1-type cytokine characterized functionally in fish. J Immunol 175:2484-2494

Submitted: October 8, 2015; Accepted: February 8, 2016 Proofs received from author(s): March 29, 2016 